\title{
Family Planning Practices of Female Garment Workers
}

\author{
Article by Shazly Bari ${ }^{1}$, Irin Hossain ${ }^{2}$ \\ ${ }^{1,2}$ National Institute of Preventive and Social Medicine, Mohakhali, Dhaka \\ E-mail: irin.hossain@gmail.com ${ }^{l}$
}

\begin{abstract}
A cross sectional descriptive study was carried out among the garments workers with the objective to assess the family planning practices of female garment workers with structured questionnaire by face to face interview. The proportion of women seeking abortion was $75 \%$. The proportion of female workers were using family planning method was $85 \%$ and rest of workers were not using any type of method is 15\%. Among those 15\% who were using family planning method and apart from them $76.5 \%$ were taking OCP and $70 \%$ providing by Govt. source. There were also some garment workers who were concern about family planning method but due to long term use of oral contraceptive pills as contraceptive method leading to many chronic diseases. This study reflected family planning practices of female garment workers, for better standard. Further large scale studies needed to explore.
\end{abstract}

Keywords: Family planning practice, female garment workers.

\section{Introduction}

The female garment workers are not aware about taking any family planning method leading to unwanted and recurrent pregnancy which increases the risk of spontaneous abortion, low birth weight, prematurity and so on. Despite the significant expansion of health services in the last two decades in the countryside, the health status has remained poor in Bangladesh. One major reason of high maternal morbidity in Bangladesh is the lack of maternal knowledge about the need of antenatal care and preventive measures. As they are not conscious about receiving antenatal and postnatal care as well as vaccination so they are facing various gynaecological and obstetrical problems. The main objectives of this research were to identify knowledge and behavior of adolescents about menstruation, marriage, pregnancy, family planning etc and to specify different important matters like their functional behavior, if their health problem arises where they usually go, discussion about sexual matters with anyone, their willingness to know about reproductive health.

Among the contraceptive methods, sterilization, IUD, oral pills are the most widely used methods. The proportion of couples using these three methods in developing countries is much greater than corresponding proportion in developed countries which is about $81 \%$ and $43 \%$ respectively. In developed countries condoms are used widely because they are much aware of sexually transmitted diseases and it is a fact that condom prevents both pregnancy and sexually transmitted diseases. Sterilization is the most used method accounting for over one third of the world contraceptive use. China and India have almost half of the users of his method. In general, female sterilization is more common than male sterilization and this gap is widening. Oral pill is an important method in many countries but in contrast to China and India it is relatively insignificant [1]. In Bangladesh, during 1996-97 periods, among the different methods used 50\% was oral pill, $18.3 \%$ was female sterilization $14.9 \%$ was injectables, $9.4 \%$ was condoms, $4.3 \%$ was IUD, $2.7 \%$ was male sterilization, and $0.2 \%$ was implants. But in India $75.1 \%$ taken female sterilization as a method of choice oral pill. In Indonesia oral pill and injectables were methods of choice accounts respectively $28.2 \%$ and $38.6 \%$ [2]. Only $7 \%$ women had unmet need for family planning. 18\% discontinued use within 12 months mainly among the pills, condoms and traditional users.

Study shows the socioeconomic and geographical differentials in use of contraception in general terms, contraception for spacing varies more widely than for limitation of the family size. Urban, well-educated and wealthier respondents were much more like to use reversible methods to postpone the next birth than their rural, less educated and poorer counterparts [3]. The timing of female first 
marriages in relation to menarche shows an appreciable minority (28\%) of women age 45-49 reported that their first marriage occurred before menarche [4]. Traditionally, Bangladesh has been characterized by exceptionally early marriage for female and large age differences between husbands and wives. This situation is changing steadily. Female age at marriage has risen from about 16 years in the mid-1970s to about 18 years in 1989. About $60 \%$ of the Bangladeshi women were married by the time they were age 15 years. The median age of first marriage among the women 20-49 is 14 years. There has been slow but steady increase of first marital age among the women over past 25 years. The median age at first marriage increased from 13.3 among the women currently age 45-49 to 15.3 for those aged 20-24 years. Only one-half of the adolescents were aware of various family planning methods, and young people's knowledge about spacing methods, such as through the use of intrauterine devices (IUDs) or oral contraceptive pills, was very low. In India, high fertility rates, high rates of teenage pregnancy, high risk of STI/HIV, and poor nutritional status are the main health problems among the adolescent population. High fertility is related to early marriage [5].

\section{Methods}

\section{Study design and sample}

This study was conducted to assess the family planning practices of female garment workers at Meherun Apparels Ltd Malibag, Dhaka according to the following methodologies:

A semi structured questionnaire was used as research instrument. The questionnaire development: based on the specific objectives of the study, at first variables were identified. Data were collected by face to face interview, by asking them questions as per the written questionnaire at the factory. The study populations were interviewed one after another without disturbing their routine works. The interview was taken by the researcher herself at the site of the study.

\section{Analysis}

Collected data were analyzed after thorough checking, cleaning, editing and compiling by using the SPSS (Statistical package for social science, version 24 for windows) software the test statistics was used to analyze the data are descriptive statistics and inferential statistic according to the demand of the study with $95 \%$ confidence interval. Level of significance was set at 0.05 . Qualitative data were analyzed on the basis of themes.

\section{Result}

This was a cross sectional study, conducted among the female garment worker.

\section{Distribution of the respondents by history of unplanned or unwanted pregnancy $n=152$}

Out of the total 152 respondents who had children, majority (70\%) of them had no history of unplanned or unwanted pregnancy and less than one third (30\%) had history of unplanned or unwanted pregnancy.

Table 1. Distribution of the respondents by history of unplanned or unwanted pregnancy

\begin{tabular}{|l|l|l|l|}
\hline $\begin{array}{l}\text { History of unplanned } \\
\text { or unwanted } \\
\text { pregnancy }\end{array}$ & $\begin{array}{l}\text { History of } \\
\text { unplanned or } \\
\text { unwanted } \\
\text { pregnancy }\end{array}$ & Frequency & Percentage \\
\hline No & 152 & 106 & 70 \\
\hline Yes & & 46 & 30 \\
\hline Total & & 152 & 100.0 \\
\hline
\end{tabular}

\section{Distribution of the respondents by family planning practice $\mathbf{n}=\mathbf{2 0 0}$}

Out of the total 200 respondents most of them 170 (85\%) found to take contraceptive method and only $30(15 \%)$ did not practice contraceptive method. Out of the total 170 respondents who had history of taking contraceptive method more than half 90 (53\%) had started taking contraceptive 
method just after marriage, more than one third 60 (35\%) had started after first child birth and only more than one tenth $20(12 \%)$ had started after last child birth. Out of the total 200 respondents most of them $130(76.5 \%)$ took oral pills. Out of the total 130 respondents who use oral pill most of them $91(70 \%)$ got contraceptive pill from government source and $39(30 \%)$ got from non govt. source. Out of the total 99 respondents most of the respondents 90 (99\%) got government contraceptive pill by free of cost and only $1(1 \%)$ was not free.

Table 2. Distribution of the respondents by family planning practice

\begin{tabular}{|l|l|l|}
\hline $\begin{array}{l}\text { Practice of } \\
\text { contraceptive method }\end{array}$ & Frequency & Percentage \\
\hline Yes & 170 & 85 \\
\hline No & 30 & 15 \\
\hline Time of starting contraceptive method n= 170 \\
\hline After marriage & 90 & 53 \\
\hline After first child birth & 60 & 35 \\
\hline After last child birth & 20 & 12 \\
\hline Type of contraceptive use n= 170 \\
\hline Oral pills & 130 & 76.5 \\
\hline Condom & 15 & 8.8 \\
\hline Depo provera & 5 & 3 \\
\hline Copper T & 18 & 10.6 \\
\hline Norplant & 2 & 1.2 \\
\hline Source of getting contraceptive pill n= 130 \\
\hline Govt. & 91 & 70 \\
\hline Non-govt. & 39 & 30 \\
\hline Expense of Government oral pill \\
\hline Not free & 1 & 1 \\
\hline free & 90 & 99 \\
\hline
\end{tabular}

\section{Distribution of the respondents by problem in using oral pill and type of problem}

Out of the total 130 respondents who used oral pill half of the respondents 67 (51.6\%) had problem in using oral pill and $63(48.4 \%)$ had no problem in using oral pills. Out of the total 130 respondents who used oral pill majority $88(68 \%)$ had developed vertigo in using this method.

Table 3. Distribution of the respondents by problem in using oral pill and type of problem

\begin{tabular}{|l|l|l|}
\hline $\begin{array}{l}\text { Problem in using } \\
\text { this method n= 130 }\end{array}$ & Frequency & Percentage \\
\hline No & 63 & 48.4 \\
\hline Yes & 67 & 51.6 \\
\hline Types of problem n= 91 & 88 & 68 \\
\hline Vertigo & 8 & 6.15 \\
\hline Headache & 8 & 2.3 \\
\hline Nausea or vomiting & 3 & .76 \\
\hline Weight gain & 1 & 13.07 \\
\hline Weakness & 17 &
\end{tabular}

Distribution of the respondents by consultation about gap between children with husband $n=$ 152

Out of the total 152 respondents who had one child, two child or more, most of them $114(75 \%)$ talked about gap between two children and one forth 38 (25\%) did not consult with their husbands. 
Table 4. Distribution of the respondents by consultation about gap between children with husband

\begin{tabular}{|l|l|l|}
\hline $\begin{array}{l}\text { Consultation about } \\
\text { gap between } \\
\text { children with } \\
\text { husband }\end{array}$ & Frequency & Percentage \\
\hline No & 38 & 25 \\
\hline Yes & 114 & 75 \\
\hline Total & 152 & 100.0 \\
\hline
\end{tabular}

Distribution of the respondents by knowledge about emergency contraceptive $\mathbf{n}=\mathbf{2 0 0}$

Out of the total 200 respondents, majority 136 (68.0\%) had no knowledge about emergency contraceptive and 64 (32.0\%) had knowledge about emergency contraceptive.

Table 5. Distribution of the respondents by knowledge about emergency contraceptive

\begin{tabular}{|l|l|l|}
\hline $\begin{array}{l}\text { Knowledge about } \\
\text { emergency } \\
\text { contraceptive }\end{array}$ & Frequency & Percentage \\
\hline No & 136 & 68.0 \\
\hline Yes & 64 & 32.0 \\
\hline Total & 200 & 100.0 \\
\hline
\end{tabular}

\section{Discussion}

The study was carried out to describe the family planning practices of female garment workers in selected garment factory. The study was done to assess the family planning practices of female garment workers.

Out of the total 152 respondents who had children, majority (70\%) of them had no history of unplanned or unwanted pregnancy and less than one third (30\%) had history of unplanned or unwanted pregnancy. Most of them $170(85 \%)$ found to take contraceptive method and only 30 (15\%) did not practice contraceptive method. Out of the total 170 respondents who had history of taking contraceptive method more than half 90 (53\%) had started taking contraceptive method just after marriage, more than one third $60(35 \%)$ had started after first child birth and only more than one tenth $20(12 \%)$ had started after last child birth. most of them 130 (76.5\%) took oral pills.

Out of the total 130 respondents who use oral pill maximum of them 91 (70\%) got contraceptive pill from government source and 39 (30\%) got from non govt. source. Out of the total 99 respondents most of the respondents 90 (99\%) got government contraceptive pill by free of cost and only $1(1 \%)$ was not free. Out of the total 130 respondents who used oral pill half of the respondents $67(51.6 \%)$ had problem in using oral pill and $63(48.4 \%)$ had no problem in using oral pills. Out of the total130 respondents who used oral pill majority $88(68 \%)$ had developed vertigo in using this method. Out of the total 152 respondents who had one child, two child or more, most of them 114 (75\%) talked about gap between two children and one forth 38 (25\%) did not consult with their husbands. Majority 136 (68.0\%) had no knowledge about emergency contraceptive and $64(32.0 \%)$ had knowledge about emergency contraceptive. Out of the total 27 respondents, majority $12(40.74 \%)$ had taken ANC in upazila health complex, $6(22.22 \%)$ in private doctor and $9(33.33 \%)$ in other places.

\section{Conclusion}

The awareness of family planning as a way to reduce unwanted birth was found universal amongst eligible women in Bangladesh. However, not all women were equally aware about the family planning methods. Oral pills and condoms were widely known but the other methods such as injections, ligations, vasectomy and other methods were not well known.

\section{Acknowledgement}

I am extremely grateful to my respected teacher Assistant Professor Dr. Md. Shafiur Rahman my supervisor for his continuous support and scholarly guidance despite his busy schedules. Without his 
valuable advices, constructive suggestions, passion and whole-hearted co-operation, I could never have completed it in time.

I express my sincere gratitude to Prof. Manzurul Haque Khan, PhD, Program in charge MPH $(\mathrm{OEH})$

\section{References}

[1]. Acharya Dev Raj, Bhattarai Rabi, Pobalan Amuda, van Teijlingen, Edwin R, Chapman Glyn (2010) on Factors associated with teenage pregnancy in south asia in Health science Journal, vol 4, issue 1.

[2]. Candan Iltemir, Ozturk Turhan, Yuksel Onaron, Ilknur Gumus, Hilal Yuvaci, Elif Gozdemir (2010), on Adolescent Pregnancies: Maternal and Fetal Outcomes. The new Journal of Medicine; vol 27; pp 113-116.

[3]. Chabra, S on Perinatal outcome in Teenage Mothers. The journal of Obstetrics and Gynaecology of India, Feb 1991, vol 41(1), pp 30-32.

[4]. Prianka Mukhopadhyay, R. N. Chaudhuri and Bhaskar Paul on The Hospital based perinatal Outcomes and complications in Teenage Pregnancy in India, (2010); October, vol 28(5); pp 494-500.

[5]. Rahman MM, Akter S, Mondal MNI on Contraceptive Use among Married Women in Chuadanga District, Bangladesh. Meddle East Journal of Family Medicine (2008); Vol 6(2), pp 40-45. 